\begin{tabular}{|l|l|l||}
\hline \multicolumn{2}{|c|}{ PublisherInfo } \\
\hline \hline PublisherName & $:$ & BioMed Central \\
\hline \hline PublisherLocation & $:$ & London \\
\hline \hline PublisherImprintName & $:$ & BioMed Central \\
\hline \hline
\end{tabular}

\title{
An interferon-inducible gene in lupus susceptibility
}

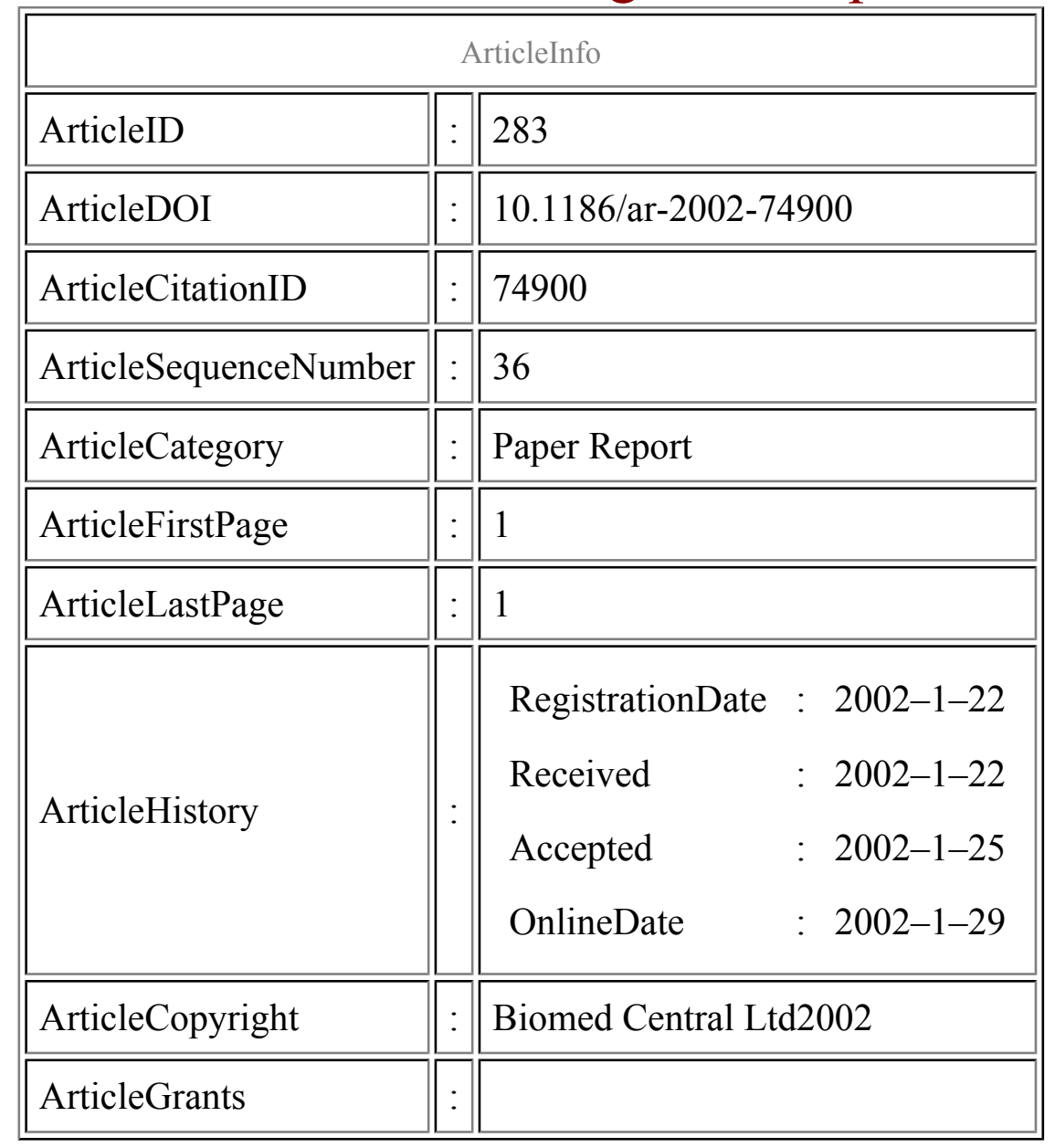




\begin{tabular}{|l|l|l||}
\hline ArticleContext & $:$ & 130754411 \\
\hline
\end{tabular}

Floris van Gaalen, ${ }^{\text {Affl }}$

Aff1 Department of rheumatology, LUMC, Leiden, Netherlands

\title{
Keywords
}

\author{
genetics, inbred mice, lupus, microarray
}

\section{Contex}

Crossing New Zealand Black (NZB) and New Zealand White (NZW) mice generates one of the most studied animal models of human systemic lupus erythematosus (SLE). Genetic analyses have revealed that this model shares with human lupus a complex genetic basis. One locus that is consistently linked with lupus traits is the distal chromosome 1 locus known as the $\mathrm{Nba} 2$ locus (New Zealand black autoimmunity 2). In this paper the $\mathrm{Nba} 2$ locus was investigated for the presence of susceptibility genes. Nonautoimmune C57BL/1 (B6) mice were made congenic for $\mathrm{Nba2}$. Subsequently, the congenic mice were crossed with NZW mice. Spleen cells from the B6.Nba2 animals were used to screen for candidate genes using oligonucleotide microarrays.

\section{Significant finding}

The B6.Nba2 congenic mice developed high levels of autoantibodies but only a small number developed lupus nephritis. However, offspring of the B6.Nba2 congenic mice crossed with NZW mice developed high levels of antibodies and severe lupus nephritis similar to NZB x NZW mice. Expression profiling of spleen cells of the B6.Nba2 mice showed only two differentially expressed genes, interferon-inducible genes Ifi202 and Ifi203. In B6.Nba2 mice, Ifi202 levels were higher whereas Ifi203 levels were lower than in controls. More importantly, both genes are located in the Nba2 interval. Quantitative PCR showed that Ifi202 transcripts are specifically increased in B cells and non T/non B cells of B6.Nba2 spleen cells.

\section{Comment}


Ifi202 and Ifi203 belong to the Ifi200 gene cluster. This family of genes encodes structurally related proteins that may be induced by interferons. These cytokines have been shown to enhance murine lupus and SLE. Increased Ifi202 expression inhibits cell proliferation. The authors suggest that inhibition of apoptosis of B cells, which showed increased levels of Ifi202, may be the underlying mechanism by which Ifi202 contributes to lupus susceptibility.

Taken together these results implicate Ifi202 as a candidate gene in murine lupus susceptibility. This offers potential insight to disease pathogenesis, in particular suggesting a potential pathway to disease expression through dysregulation of B-cell survival. An important proviso however is the necessity to now demonstrate similar involvement of this gene family in human SLE itself.

\section{Method}

Mouse models - generation of congenic strains, microroarray, PCR

\section{Additional informatio}

Kono DH, Burlingame RW, Owens DG, Kuramochi A, Balderas RS, Balomenos D, Theofilopoulos AN: Lupus susceptibility loci in New Zealand mice. Proc Natl Acad Sci USA 1994, 91:10168-10172.

Landolfo S, Gariglio M, Gribaudo G, Lembo D: The Ifi 200 genes: an emerging family of IFNinducible genes. Biochimie 1998, 80:721-728.

\section{References}

1. Rozzo S, Allard J, Choubey D, Vyse T, Izui S, Peltz G, Kotzin B: Evidence of an interferoninducible gene, Ifi202, in the susceptibility to systemic lupus. Immunity. 2001, 15: 435-443.

This PDF file was created after publication. 